\title{
Social Positioning in Teacher-Student Interactions: A Linguistic Ethnographic Investigation
}

\author{
Longji Christopher Gonsum ${ }^{1} \&$ Cise Cavusoglu ${ }^{1}$ \\ ${ }^{1}$ Department of English Language Teaching, Faculty of Arts and Sciences, Near East University, Turkey \\ Correspondence: Longji Christopher Gonsum, Department of English Language Teaching, Faculty of Arts and \\ Sciences, Near East University, Near East Boulevard, 99138, Nicosia/TRNC, Mersin 10, Turkey. E-mail: \\ chrisgonsum.longji@neu.edu.tr
}

$\begin{aligned} & \text { Received: December 19, } 2018 \quad \text { Accepted: January 19, } 2019 \text { Online Published: March 2, } 2019 \\ & \text { doi:10.5539/ijel.v9n2p332 }\end{aligned}$ URL: https://doi.org/10.5539/ijel.v9n2p332

\begin{abstract}
From a social constructionist perspective and using Positioning Theory, this study examined the interactional strategies that interactants use in establishing their social positions in interactions in a registration office. Linguistic ethnographic methods were deployed where naturally occurring interactions of 30 participants in a registration office in a Nigerian university located in North-Central Nigeria were collected through audio-recordings, which added up to 177 minutes in total. Stimulated recall interviews were also conducted with some of the interactants to refute or validate the results of preliminary analyses of their interactional strategies. Micro-discourse analysis was adopted for the analysis of both the ethnographic and discourse data in order to account for the influence of context and other nonverbal behaviours on the interactants' choices and the discourse data. The study revealed that sociocultural expectations, knowledge and perceptions significantly influenced the choice of the interactional strategies used for the negotiation and construction of social positions by both the teachers and the students in their interactions. The study also showed the discursive variables of power relations and ages of the interactants as impacting on their use of face acts as deliberate social positioning strategies in the interactions. The study concludes that interactants' pragmatic awareness of context is crucial in establishing their negotiated positions in meaningful and cordial interactions.
\end{abstract}

Keywords: discursive strategy, face acts, linguistic ethnography, power relations, social positioning

\section{Introduction}

\subsection{Interactions as Discursive Negotiation of Social Positions}

The school environment is typically a "social space" (Bourdieu, 1985) where the forces of power relations are brought in direct contact with each other especially during face to face interaction. The Nigerian sociolinguistic landscape, like that of many other countries is divided along the lines of the social constructs of power, gender, ethnicity and many other forms of identities (Akere, 2008) and the elements of power relations such as social status and age are emphasised and known to greatly impact on interactions (Adegbija, 1993; Odebunmi, 2013). This article is therefore interested in the use of discursive strategies by Nigerian university teachers and students as a social positioning strategy in naturally occurring interaction in a Registration office of a Nigerian university. Firstly, the article aims at investigating how interactants take or claim social positions as well as how they fashion out and demand their social positions in their interactions. Secondly, the article aims at revealing these discursive strategies as intentional interactive acts that enable the teachers and students to discursively negotiate their social positions in interactive encounters within the imposing power relations of the existing context. Although there have been many studies regarding teacher-student interaction, they have concentrated more on classroom interaction (for example, Kraker, 2000; Rumenapp, 2016). However, little attention has been paid to naturally occurring interaction between the teacher and the student in other spaces such as an office especially in Nigeria, where interactive acts are tied to sociocultural expectations. Furthermore, the interaction between the teacher and the student in Nigeria occurs within an asymmetrical power relation with divergent sociolinguistic implications. The face to face nature of the interaction meant that interactants have to be strategic in terms of their utterance choices and other nonverbal acts in executing their intended objectives.

In every given interaction, interactants are representatives of certain groups with assumed rights, duties and obligations that have been condensed and crystallised over many years of discursive narrations. These rights, 
duties and obligations are seen in how they are executed differently by the interactants in interactions in the form of requests, apologies, and salutations and so on. The teacher and the student dichotomy in a school setting typifies such group membership with a long list of identifiable traits that set them apart in terms of their social positions in interaction. Between the teacher and the student are differences that are defined by their social ranking, duties and obligations in the school context which invariably defines their positions. These differences are reflected in the interactional strategies that they both employ when they are interacting with one another relative to their social positions in any particular episode of talk/interaction. Social positioning theorists have argued that social positioning is the "discursive construction of personal narrations" and actions of one's self relative to others as their interest converges or diverges (Tirado \& Gálvez, 2007, p. 8).

\subsection{Interaction in the School Setting}

The interactions of teachers and students in a social space like the Registration Office are negotiated within certain constraints that the context and other sociolinguistic expectations places on the interactants regarding appropriacy etiquette. This view is echoed by Fairclough (2001) that discourse (interaction) is a social practice that has sociocultural implications on the interactants. Similarly, Bourdieu $(1985$, p. 723$)$ believe that the social space has many dimensional forces and objective power relations "that impose themselves on all who enter the field and that are irreducible to the intentions of the individual agents or even to the direct interactions among the agents". The divergence or convergence of the interests and intentions of these interactants is expected to be managed in different episodes of social encounters. In order to manage these diverging or converging interests, interactants employ various strategies during interactions. The pragmatic awareness of the interactants regarding the various constraints that the context places on them is crucial in enabling them navigate the complexities associated with interaction especially in a power sensitive environment such as the Nigerian university context.

\subsection{Social Positioning Theory in Interaction}

Harré (2004, p. 6) defines Positioning Theory (PT) in social psychology as the "study of the way rights and duties are taken up and laid down, ascribed and appropriated, refused and defended in the fine grain of the encounters of daily lives". These duties and rights are tied to interactants statuses and biological differences and are constantly being negotiated by the interactants, with the human language serving as the medium for the negotiation and execution of these duties and rights in daily encounters. Moghaddam, Harré and Lee (2008) believe that the ability to perform any given act is tied to a person's psycho-symbiosis knowledge of indexicality and historicity of elements of context. This view is aptly captured by van Dijk (2008) as context model (CM). A $\mathrm{CM}$ is defined as the sum of mental models that interactants find relevant in talk (van Dijk, 2008). The relevance of a CM to social positioning is that it serves as an important asset to the interactant in knowing where they stand and helping them to work around expected expectations in a given situation.

PT is believed by Tirado and Gálvez (2007) to have emerged from social psychology as an interactionalist approach to account for the moral order of the constantly changing episodes of daily existence of interactants as they negotiate for their positions. A position according to Badarneh and Migdadi (2018, p. 95) "shows how participants discursively inscribe themselves in contexts of interaction, which is simultaneously relational as positioning determines how the participants establish relationships with each other". Harré and van Langenhove (1999) contend that a position has personal, group, intergroup and sociocultural attributes that are woven into its manifestation in interaction. As a social constructionist perspective, it sheds light on the underlying factors that informs and shapes interpersonal interactions. The social cognitive dimensions that the theory brings in relation to daily human problems have seen it being used in various domains of contemporary researches.

Using PT within the sphere of politics, peace and conflict resolution, Cairnie (2010) demonstrated the changing positions of President Bush's political staff in their efforts in handling the Water Gate political crisis of 1993. Cairnie (2010) contend that these political staffs have had to shift to different positions when they are confronted by the press and when they are summoned by their employer, President Bush. Similarly, by focusing on political processes and conflictive or conciliatory narratives of a people, Moghaddam and Harré (2010) uncovered through the use of PT how the distribution of rights and duties of the people is fused into the discursive actions (interactions) of the people which could yield to conflicts or peace. Badarneh and Migdadi (2018) examined how social media online comments of Jordanians revealed the various social positions they take on topical national political issues. Although the rights and duties associated with different interactants are known, they are not constitutively fixed; they are fluid and constantly changing. It is this fluidity that causes different levels of interactional conflicts giving rise to what van Dijk (2008) refers to as a situation. The 'situation' is not a direct link between discourse and society but the relative and relevant influence that subjective constructs of "social situations have on the language use relative to the language users" (van Dijk, 2008, p. 3). It seems right then, the 
claim by Badarneh and Migdadi (2018) that in a given social situation, there are numerous positions that could emerge as direct, indirect and malignant positions, where for example, direct position could relate to direct insults, indirect position relates to indexical representations while malignant position relates to derogatory representations such as is in pro racist laws. Understanding these positions according to Tan and Moghaddam (2007), requires a good grasp of how cultural factors shape and affect the practice of positioning at different levels.

In order to account for the sociocultural aspects of context, Goffman (1967) and Rampton (2015) argue that when examining interactional discourse data, it is important to come to grasp with the social situation: the persons and the entire relevant physical aspects of the ongoing interaction which could be focused or unfocused. The interactants in a focused social situation are directly involved in the interaction while those in the unfocused interaction are present but only gleaning for information in the course of an ongoing interaction. The discursive strategies that these interactants use in a social situation in order to execute their locutionary rights, duties and obligations are influenced significantly by considerations of the social characteristics of the other interactants.

\subsection{Positioning and Face Acts}

Face, much like positioning is constantly being negotiated in interaction. Face is defined by Goffman (1967) as a complex web of 'interactional order' that has various social ramifications regarding its manifestation in interactions. Locher and Watts (2005) conceived face as the embodiment of our social knowledge that is manifested in multifaceted and indeterminate ways. According to Locher and Watts (2005, p. 12), "Faces, in other words, are rather like masks, on loan to us for the duration of different kinds of performance". Face in effect is used to initiate, establish, forge, maintain and achieve relationships and it is used to serve our relational needs such as establishing our positions in everyday interaction. Many scholars (Arundale, 2010; Locher \& Watts, 2005) have recognised the emergence of face as a significant contribution of Brown and Levinson (1987) to the theory of politeness that see face as "something that is emotionally invested, and that can be lost, maintained, or enhanced and must be constantly attended to in interaction" (p. 311) with its manifestation in terms of being 'negative' or 'positive'. Similarly, Arundale (2010) sees face acts as constitutive of behaviours of the interactants that show 'convergence' or 'divergence' in the interaction and it is manifested in three positions of threat, support or stasis. In other words, these are identifying positions that interactants could take in an interactional episode.

Bousfield (2008), on the other hand, sees face threatening acts as deliberate face attack or acts of impoliteness that are demonstrative of the position of the 'threatener' causing the other interactant to lose face. Locher (2008) and Culpeper (2011) have presented face threat as strategic tool of negotiating positions in interactions. Face threatening acts between interactants of equal social standing may result in a counter threat hence a counter position but a threat from a teacher to a student may only lead to a face loss. A face threat from a teacher to a student could be as a result of showing his disapproval of an act, hence, a divergence with the act and positioning himself as the power figure against the student's position. In a power sensitive context such as the Nigerian university environment, where age and social status have direct and indirect repercussions on the negotiation of social positions in the interactions between lecturers and students; face manifestations are deliberate tools of social positioning of the interactants. Using data from online media responses, Upadhyay (2010) contend that language users are sometimes deliberately impolite in order to establish their identity and positions, especially because there is less face to lose on the online platform. Summarily, the positions taken or given during interaction provide an insight into the interpersonal, intergroup and intragroup relationships of the interactants.

\section{Method}

Linguistic Ethnography (LE) was adopted as a methodology in this study in order to investigate the context of the study as well as to adequately account for the linguistic and paralinguistic data that demonstrates the face acts that lead to positioning in the interactions. Our choice of LE is tied to Rampton (2015) who believes that discourse is only an aspect of interactional data. The social context is equally a significant component of discourse whose understanding will depend on the ethnographic investigation of all its aspects. Additionally, the use of LE has enabled us to present the various episodes of the interactions from an up-close and emic point of view thereby making it possible for us to account for the negotiations of interactants position. We have also incorporated stimulated recall interviews (SRIs) with some of the interactants in order to clarify on what we considered as critical incidents during the interaction. Both Rampton (2006) and Copland (2015) have emphasized the significance of ethnography in revealing the very important yet unspoken aspects of interactions such as facial expressions, gestures, long pauses, tone of the voice among others. 


\subsection{Data Collection}

The data were collected from North-Central Nigeria in a university during the registration process of newly admitted students into a department of the university. A mini audio-recorder was used to record the naturally occurring interactions between the students and the registration officers who were equally lecturers in the department. The recorded data were subsequently transcribed to account for the linguistic data. Field-notes were used to record our observation of the performance of the interactants and other significant paralinguistic moves of the interactants. The observational data were used to support the linguistic data in terms of providing the desired contextual cues that relate directly with the entire interaction. SRI sessions were also used to validate or to refute certain initial claims that we made regarding the interpretation of the data. We chose to collect our data in this specific office because it offered unobtrusive access for the collection of the data since one of the researchers was also a staff member of the department at the time of data collection. Secondly, since there were other registrations points, it provided anonymity to the researchers, i.e., even though the students were informed about all the relevant data collection procedures and tools, they were not told the specific office and time that the recording would be done, nor were they told who would be doing the actual recording. This was aimed at making the interactions as authentic as possible. They were later debriefed during the SRI sessions.

\subsection{Participants' Characteristics}

The recording of the interactions lasted for six weeks. Interactions of 28 students and two lecturers were recorded making up 30 participants and the entire recording lasted for 177 minutes 57 seconds. The lecturers, Mr. John and Mr. Jude (pseudonyms), were between the ages of 34 and 45 and were performing task of students' registration during data collection. The students were all newly admitted students who had enrolled for the degree programme of the department, while the lecturers were employees of the university and had been working with the university for over five years. The students were between ages 18 and 23. Majority of them had recently graduated from secondary schools. For the purpose of registration, the students were expected to present their admission letters, secondary school results and other supporting documents for authentication to the registration officers.

\subsection{Stimulated Recall Interview Procedure}

Fifteen interactants participated in the SRI sessions (two lecturers, nine female and four male students). The SRI sessions consist of playing back a portion of a given interaction and asking the interactants questions regarding specific choices that they have made during the interaction and what they felt about our initial and preliminary interpretation of their interactional acts so that they can refute or validate our claims. The SRI sessions in this study were held with interactants based on the critical or significant pairs of greeting-greetings, offence-reprimand and question-answer that related to the positioning of the interactants as they emerged from the data. The selected pairs were chosen after a preliminary interpretation of both the ethnographic and discourse data that demonstrated face acts which led to certain social positionings of the interactants.

\subsection{Data Analysis}

We have employed the Jeffersonian Transcription Notation (Jefferson, 1984, see the Appendix A for the Transcription Notation) for the transcription of the audio-recorded data. The ethnographic data (represented in double parenthesis) were then used to flesh up the linguistic data since we view ethnographic data to be as important as the linguistic data. Micro Discourse Analysis (MDA) and LE were subsequently used for the layer by layer analysis of both the linguistic and ethnographic data. The choice of MDA and LE was based on the assumption that both LE and MDA are methods that view discourse as composite in nature (Rampton, Maybin, \& Roberts, 2015) and the capturing of the occurrence of interactional acts in real time can provide more insight into the operation and organisation of talk and interaction. Our aim is to investigate the actual practice of interactional duties and obligations and indeed the taking up and giving of positions in interactions by looking at how language and social positioning practice coexist in a given speech event. The larger methodological framework of LE is primarily employed because of its accommodating nature and we believe that such a method will marry seamlessly with our guiding frameworks of positioning in interaction.

We have relied on Leech's (2014, p. 121) categorization speech events, where "speech events tend to group themselves into pairs of opposites, for example, offer versus request, thanks versus apology" with evidence from our data. This seems to also confirm the possible existence of two positions in interactions. In order to investigate the acts of positioning by the interactants, we have isolated three acts; greetings, reprimands and apologies. The simultaneous presentation and interpretation of both the linguistic and ethnographic actions, manners, attitudes, reactions and other non-verbal moves as recommended by Rampton, Maybin and Roberts (2015) was made possible through a combination of MDA and LE techniques. . 


\section{Results}

\subsection{Direct Positioning and Face Threat Negotiations Through Reprimand-Apology}

Badarneh and Migdadi (2018) identified face attack as a form of direct positioning. The acts of direct positioning are evident in conflictive interactions where interactant try to impose or assert their views. In face to face interaction, reprimands are often representation of direct positioning with apology responses serving as redressives or face saving acts. An apology is a strategic means of making amend, achieving redress in interaction and gaining positive face. As "behavatives" (see Austin, 1962), when apologies are uttered, they convey a meaning that are aimed at achieving specific goals such as, appeasing, misleading, convincing or redressing some unintended wrongs. This point is emphasized by Efe and Forchtner (2015) by recognizing that apologies are valid means of achieving "reconciliation, redressing past mistakes..." (p. 236). Leech (2014) believes that treating apologies as just a unit of utterance without paying attention to the preceding or following up units of utterances or indeed the entire speech event is problematic, hence the need to view apology within the frame of acts of social positioning. The actualization of an effective apology in naturally occurring interaction is reinforced by a lot of contextual and extra-linguistic variables such as tone of the voice, facial expressions and other meaning attributing and deriving gestures. In most instances, apologies are produced as counter moves resulting from an initial failure using various strategies of either saying "sorry" or providing an excuse or rationalising the failure or committal of an unintended act (Leech, 2014).

Reprimands on the other hand are discursive show of disapproval as well as a response and positioning strategy to a given offense in an interaction. Leech (2014) states that reprimands have the metapragmatic function of scolding, disapproving and showing a lack of harmony with an interlocutor as a result of a failure or an offense by the interlocutor. The construction of reprimands in interaction differs from context to context and person to person. A discursive perspective of reprimands reveals that reprimands could be directly or indirectly given to the perceived offender. Direct reprimands are accompanied by direct modals such as 'should' and 'will' while indirectly reprimands are presented with hedging tactics so that the hearer is left to make implicatures or factor out the meaning of what has been said. The polite use of reprimand is a deliberate social positioning strategy that shows disapproval yet a concern for the face of other in interaction (van Der Bom \& Mills, 2015).

\subsubsection{Extract 1}

This extract is chosen among five other extracts from our data set of 28 recorded interactions that presented evidence of overt apology as an interactional response and positive positioning strategy. This particular extract is unique in the sense that it presents critical incidences of the student leaving his credentials outside, not having the original of his credentials and not arranging the credentials in an orderly manner which attracted reprimand from Mr. Jude and positioned Kay negatively before the teacher. We have chosen one of the critical incidences (not arranging his credentials) in order to account for the negotiation of direct positioning in the course of the interaction as seen in the extract below.

1) Mr. Jude: Please can you share them equally ((Handing Kay his file to sort them out))

2) Kay: ((collects his file and begins to sort out the credentials frantically))

3) Mr. Jude: (0.2) let me see them (0.2) and your passport $\downarrow$ ?

4) Kay: Here are they [sic] ((handing over two copies of passport size photos))

5) Mr. Jude: It's only a copy ((returning a copy of passport to Kay))

6) Kay: They said two? (0.2) two ((still sorting out his credentials as he fidgets with papers))

7) Mr. Jude: Please do that fast (0.2) ((almost irritably)) (0.5) just look at what you are doing $\downarrow$

8) Kay: Sir $\downarrow$ It's just today that I collected them ((still trying to arrange the documents while

9) sounding apologetic))

10) Mr. Jude: But it doesn't matter; it doesn't matter ((putting his hands across his chest)). You

11) should have organized yourself before coming in here $\downarrow$ ((looking sternly at Kay while talking

12) slower and picking his words)) [eh

13) Kay: I am] so so sorry we are bereaved that's why ((sounding very low

14) while handing out the documents with both hands))

15) Mr. Jude: ((stretching his hands and collecting the documents while looking at kay)) 
16) Kay: I said I am sorry $\downarrow$ we are bereaved that's why sir ((looking to the ground))

17) Mr. Jude: You are bereaved $\uparrow$ ((looking at Kay curiously))

18) Kay: Yes sir

The utterance in line 1 is a directive and a command that shows Mr. Jude returning a set of credentials to Kay to put them in order. This particular act is equally an expression of his displeasure with Kay for his lack of organization as well as socially positioning them (teacher vs student). The act has a perlocutionary force of stating "you need to be better organised" or "I can't do this for you". The act of quietly collecting the credentials to sort them out further emphasizes Kay's position as the student. In lines 3 and 4 the utterance by Mr. Jude indicates his growing impatience with the student; “(0.2) let me see them $\mathbf{( 0 . 2 )}$ and your passport $\downarrow "$ " This relates to what Badarneh and Migdadi (2018) refers to as face attack. A face attack is a direct positioning strategy that threatens the face of another interlocutor. Face threats by their nature are disconcerting and this is seen in the fidgeting manner that Kay's goes about arranging his credential. In line 4, Kay had not finished sorting the documents but in order to minimize the offense and safe his face, he quickly gave two passport photos instead of just one to Mr. Jude.

The display of negative emotion by the authority figure is also a show of power position (Mondada, 2017). In line 7, Mr. Jude's impatience is brought to the fore: "Please do that fast (0.2) ((almost irritably)) (0.5) just look at what you are doing $\downarrow$ " which also represents another incident of face attack aimed at establishing a direct position. The utterance in line 8: "Sir $\downarrow$ It's just today that I collected them" is an example of an excuse serving as an apology. Moreover, since positioning and face are discursively achieved, Kay's excuse is seen as an effort to present a positive face and a positive position before Mr. Jude. Kay's use of the honorific "Sir" is equally instructive because it is serving the function of a discourse softener as well as an apology (Leech, 2014) that helps Kay to negotiate a positive position in the interaction which echoes what Tan and Fathali (2007) refer to as reflexive positioning.

Lines 10 to 12 are another example of direct positioning by Mr. Jude through the use of a direct reprimand on Kay for not being organized: "You should have organized yourself before coming in here $\downarrow$ ((looking sternly at Kay while talking)). This statement passes a negative judgement on the organizational ability of Kay, hence a face attack. Badarneh and Migdadi (2018) contend that face attack as a direct positioning strategy can be insulting on an individual's face. Mondada (2017) noted that non-native speakers of a language tend to be less indirect in their use of taboo words and reprimands. Although English language is non-native to Nigeria it is the lingua franca and official language of the Nigerian state. The face attack witnessed here could therefore be claimed as a deliberate positioning strategy by Mr. Jude rather than an inability to effectively use the language. The ethnographic data showed that Mr Jude was visibly angry with Kay (giving him back his credentials to properly arrange them and then demanding for the credentials while the student was still sorting them out) and thus needs to reprimand Kay thereby emphasising his power position in the context.

The use of reprimands in lines 7 and lines 10 to 12 confirms Leech's (2014) and Efe and Forchtner's (2015) view of reprimands as redressives of some sorts. Kay's act of apology in line 13: "I am] so so sorry, we are bereaved that's why" showed that Kay's desire to safe his face and make redress for his inaptitude by presenting himself as someone who is mourning the demise of his aunt. The success of Kay's excuse can be understood from what Harré and van Langenhove (1999) refer to as relevant cultural background drawn from their context models to the positioning of the interactants: In Nigeria death is a serious matter that is never taken with levity or lied about. In order to gain a positive positioning Kay used a low voice and a humbling body posture while giving his credentials to Mr. Jude. Both the linguistic and paralinguistic elements in Kay's act of apology contribute in making his act of apology successful while positioning him favourably as someone who has a genuine reason to be unorganised at this particular episode. His direct apology is also attached with an excuse that is aimed at saving his face before Mr. Jude so that he will not be viewed as a careless student. Again, the nonverbal act of Mr. Jude in line 15 "((stretching his hands and collecting the documents while looking at Kay))" showed that his apology strategy worked. In Line 16: “I said I am sorry $\downarrow$ we are bereaved that's why sir” suggests Kay’s deliberate use of indirect positioning strategy as someone who is respectful and organised. The repeat of the apology with the added honorific "sir" is aimed at silencing his wrong as well as socially positioning him in a positive light.

\subsection{Indirect Positioning and Positive Face Negotiations Through Acts of Greetings}

Mondada (2017, p. 11) observed that the opening language (greetings) in an interaction "is the locus where the availability of the participants is established and where they identify themselves". Greetings in face to face interaction has the pragmatic function of gaining the attention of the other interactant(s) in different 
communicative encounters through the use of close and distant salutation elements such as head toss, eye flash, smile, body contact among other mundane strategies are as important as verbalised greetings (Mondada, 2017).

Greetings in many cultures of the world have been recognized as significant social norm and practice that begets reciprocal greeting, hence positive position. The importance of greeting is succinctly captured by Mondada (2017, p. 10) as being "the language of the encounter is discovered and chosen in situ, being established and negotiated during the very first words exchanged by the participants". Olaoye (2013) claims that in Nigeria, conversations start with a salutation and the manner of negotiating this social practice is entrenched into the social behaviours and cultural expectations of the people or the "context models" (van Dijk, 2008). Among Africans, salutation has an elaborate and indexical role in the interactional systems of the society. This socio-cultural practice is observed by (McKeown \& Zhang, 2015) as helping individuals and groups to consolidate their identities and position themselves in the interaction. Adjacency of greeting-greeting is also observed as operating in a systemic way and the turns are hugely impacted by variables such as age, power and context of a given speech event. The normal trajectory of salutation in the context of this research is that the student (the younger) salutes or extends greetings first towards the lecturers (the older). The failure to observe this nuanced practice is observed to have generated divergent or negative positioning. Greeting as the first utterance has the sociolinguistic value of socially positioning the interactants positively in speech events.

\subsubsection{Extract 2}

The extract below is chosen from 28 other extracts with the aim of elaborating on the significance of greetings on positioning in interaction. The recording took place a few minutes after another student was sent out by the teacher to go and dress up properly. In order to gain the positive face of the teacher, the student used different indirect positioning strategies. The entire data set consist of 21 instances of first position greetings by the students during the interactions but this particular extract was found to be representative of the socio-linguistic positioning strategies by both the teacher and the student and pays attention to the effect of other sociolinguistic variables such as power, context and paralinguistic actions. The extract is gotten from the first eight lines of a two minutes 15 seconds interaction.

1) ((knock on the office door, a student peeps through the open door))

2) Mr. John: Yes $\downarrow$ can you come in $\uparrow$ (0.2) Come in $\downarrow$ ((Beckoning the student with his hands to

3) come in))

4) Garos: Good morning sir ((stepping into the office with a bag in her hand))

5) Mr. John: Yes, you said what happened $\downarrow$ ((looking directly at Garos while using his pen and

6) hand to point at the empty seat for her to sit))

7) Garos: On Monday@@@ ((sounding a bit distraught))

8) Mr. John: you were not around $\downarrow$

The first act of positioning in the interaction is the positive face and nonverbal act of knocking at the door in line 1. This polite act is equally an announcement of presence (Mondada, 2017). The act of knocking on the door is interpreted as a nonverbal polite request strategy of "may I come in?" as well as being an indirect positioning strategy. In lines 2 and 3, we see a combination of both a verbal and nonverbal act of positive face and indirect position by Mr. John. The mild command, "Yes $\downarrow$ can you come in $\uparrow(\mathbf{0 . 2})$ Come in $\downarrow$ " as well as using hand gestures to urge her to step into the office is not only a politeness strategy but a vital positioning strategy that signifies the power position of Mr. John in the context. The (0.2) hesitation by Garos is also a significant indirect positioning strategy. She seemed to deliberately wait to be assigned a position by Mr. John. Her cautiousness results from the sending out of an earlier registrant by Mr. John as confirmed in the SRI. This tends to confirm the claim that in face to face interaction, Africans are general confrontation averse (Akere, 2008). The use of the indirect strategy "can you come in $\uparrow$ " clearly establishes the dichotomy of the social roles that socially positioned them even before the actual registration starts.

Although the knock on the door in line 1 is a nonverbal greeting, the actual verbalised act of salutation is seen in line 4 by Garos: "Good morning sir" in line 4 by is her first utterance that overtly expresses her greetings as well as her indirect positioning and positive face strategy. Apart from serving as an observation of the expected norm, her act of being the first to express greetings is an indirect positioning strategy that shows that Garos recognizes her position as the student and the younger person as well as recognising the power position that Mr. John occupies as the teacher in the setting. The greetings by Garos also confirms Olaoye (2013) claims that gestures of greetings are expected to be offered first by the younger interactant as discourse softeners in most 
Nigerian contexts. This proposition is confirmed by Mr. John's nonverbal action of offering a seat to Garos in lines 5 and 6 . The act of pointing at a seat to Garos is interpreted as a polite act and a positive response to her observation of the moral practice of greetings. The interaction between Garos and Mr. John shows positioning as a discursive practice of give and take. The observation of duties and obligations on the part of the younger interactant begets a positive face from the older interactant and the offering of certain rights and privileges as well.

\section{Conclusion}

This study has so far been investigating how teachers and students position themselves in naturally occurring interaction in the context of a university. We have also tried to account for nonverbal acts as composite parts of the data. Teacher-student's interactions has provided some valuable insights into how and why interactants tend to either directly or indirectly position themselves in an episode of a social encounter. We have used PT to analyse the various discursive strategies of teachers and students in interaction with the hope of uncovering what Cairnie (2010) refers to as a two-phase procedure where duties, rights and obligations to perform acts position the actors or as succinctly captured by Moghaddam and Harré (2010) that interactants use discourse to position themselves. The use of PT in this study is aimed at extending the frontier of face negotiations as a social-psychological construct that significantly contributes in the ordering of interaction in especially an African context.

Our data consist of interactions of 30 interactants', we however selected only four interactants and two extracts that exemplified the acts of both direct and indirect positioning. The chosen extracts also reflect the sociocultural significance of the acts of greetings, apology and reprimands in the negotiation of social positions in interaction. The first positioning strategy investigated is the direct positioning strategy which is made manifest through face threatening acts as seen in acts of reprimands and apology. The second strategy investigated is the indirect positioning strategy which demonstrated the significance of greetings in attaining positive face in interaction. The direct positioning strategy seemed to be aimed at addressing perceived impoliteness especially on the part of the students while the indirect positioning seemed to suggest a kind of face support as a reciprocal gesture for polite acts.

The emergence of power as a constant variable in the acts of positioning in the interactions showed that interactants seemed to position themselves relative to their power positions. PT has also showed that the identity constructs of the teachers and the students, places certain responsibilities on them. Where the students did not behave properly as seen in the analysed extracts, the teacher assumes a position of someone who has the right to address the wrongs of the students. By the students failing to comport themselves as expected, they positioned themselves against the authority figures which invariably draws a counter positioning from the teacher which is manifested as face threat towards the students.

At the level of teacher-student's relationship, the context of the registration office is believed to have positioned the student against the tide of convivial interaction. All the students we had SRI with agreed that the teachers were aggressive towards them while the teachers claimed some of the students are lacking in the required level of seriousness that the university demands. It seems evident that both the teachers and the students locate themselves from divergent poles in interaction. The Nigerian university context is a power sensitive context which also impacts on the negotiation of reprimands in interaction. Studies (e.g., Keshavarz, 2015; Leech, 2014; Mills, 2011) have shown that where hedges are used in L1 to mitigate the unpleasant effects that accompanies reprimands, most L2 speakers are ill-equipped with the pragmatic sagacity of hedging even if they are proficient L2 speakers or users, as such, people with higher social power tend to be more direct in their positioning while those with lower power are constrained to be more indirect. This probably accounts for the preponderance of direct positioning by the teachers in our data set.

Finally, the two acts of positioning that we have investigated have revealed in a new dimension the face attack that Badarneh and Migdadi (2018) identified as an act of direct positioning. This is evident in our study in the form of face threats. Direct positioning relates to Bousfield (2008) concept of deliberate impoliteness and Arundale $(2009 ; 2010)$ concept of divergence while indirect positioning relates to convergence in his face constituting theory and Leech (2014) view of politeness. Bousfield (2008) outlined the significance of addressing deliberate impoliteness as crucial to any meaningful interaction. This is especially significant in the Nigerian context where the variable of age, power and gender are known to have impacted interactions variously. The value of Positioning theory in addressing impolite acts or improper behaviour of students cannot be overemphasised, the knowledge of which can be a valuable asset to both the teachers and the students. We believe however that acts of positioning in student to student's naturally occurring interaction could offer some 
exciting perspectives regarding their strategic use of language. Again, our study was conducted on interactants that share a lot in sociocultural similarities, positioning in a multicultural setting could equally yield some exciting results.

\section{References}

Adegbija, E. (1993). Greeting norms in Nigeria and Germany: Their place in intercultural studies. Applied and Interdisciplinary Papers, 241, 1-13.

Akere, F. (2008). The English language in Nigeria: the sociolinguistic dynamics of decolonization and globalization. Ogun Journal of Arts, 14, 24-55. https://doi.org/10.4314/oye.v14i1.42450

Arundale, R. B. (2009). Face as emergent in interpersonal communication: an alternative to Goffman (pp. 3154). Equinox Publishing.

Arundale, R. B. (2010). Constituting face in conversation: Face, facework, and interactional achievement. Journal of Pragmatics, 42(8), 2078-2105. https://doi.org/10.1016/j.pragma.2009.12.021

Austin, J. L. (1962). How to do things with words. Oxford: Oxford University Press.

Badarneh, M. A., \& Migdadi, F. (2018). Acts of positioning in online reader comments on Jordanian news websites. Language and Communication, 58, 93-106. https://doi.org/10.1016/j.langcom.2017.08.003

Bourdieu, P. (1985). The social space and the genesis of groups. Theory and Society, 14(6), 723-744. https://doi.org/10.1007/BF00174048

Bousfield, D. (2008). Impoliteness in interaction (vol. 167). Amsterdam: John Benjamins Publishing. https://doi.org/10.1075/pbns.167

Brown, P., \& Levinson, S. C. (1987). Universals in language use phenomena. Cambridge: Cambridge University Press.

Cairnie, T. P. (2010). A Positioning Theory analysis of language and conflict in political processes. In M. Fathali \& H. Rom (Eds.), Words of Conflict, Words of War: How the Language We Use in Political Processes Sparks Fighting (pp. 47-68). Oxford: Praeger.

Copland, F., \& Creese, A. (2015). Linguistic ethnography: Collecting, analysing and presenting data. London: Sage. https://doi.org/10.4135/9781473910607

Culpeper, J. (2011). It's not what you said, it's how you said: Prosody and Impoliteness. In Linguistic Politeness Research Group (Ed.), Discursive approaches to politeness (pp. 57-97). Boston: De Gruyter Mouton. https://doi.org/10.1515/9783110238679.57

Efe, I., \& Forchtner, B. (2015). 'Saying sorry' in Turkey: The Dersim massacre of the 1930s in 2011. Journal of Language and Politics, 14(2), 233-257. https://doi.org/10.1075/jlp.14.2.03efe

Fairclough, N. (2001). The discourse of new labour: Critical discourse analysis. In M. Wetherel, T. Taylor \& S. J. Yates (Eds.), Discourse as data: A guide for analysis (pp. 229-266). London: The Open University.

Harré, R. (2004). Discursive Psychology and the boundaries of sense. Organisation Studies, 25(8), 1435-1453. https://doi.org/10.1177/0170840604046351

Harré, R., \& Langenhove, L. v. (1999). The dynamics of social episodes. In R. Harré \& L. van Langenhove (Eds.), Positioning theory: Moral Contexts of Intentional Action (pp. 1-14). Oxford: Blackwell.

Jefferson, G. (1984). Transcription Notation. In J. Atkinson \& J. Heritage (Eds.), Structures of Social Action: Studies in Conversation Analysis (pp. 198-250). New York, NY: Cambridge University Press.

Keshavarz, H. M. (2015). Contrastive analysis and error analysis. Tehran: Rahnama.

Kraker, M. J. (2000). Classroom discourse: Teaching, learning, and learning disabilities. Teacher and Teacher Education, 16(3), 295-313. https://doi.org/10.1016/S0742-051X(99)00063-3

Leech, G. N. (2014). The pragmatics of politeness. Oxford: Oxford Studies in Sociolinguistics; https://doi.org/10.1093/acprof:oso/9780195341386.001.0001

Locher, M. (2010). Relational work, politeness, and identity construction. In G. Antos \& E. Ventola (Eds.), Handbook of Interpersonal Communication (pp. 509-540). New York, NY: De Gruyter Mouton.

Locher, M. A., \& Watts, R. J. (2005). Politeness theory and relational work. Journal of Politeness Research, 1(1), 9-33. https://doi.org/10.1515/jplr.2005.1.1.9 
Locher, M., \& Bousfield, D. (2008). Impoliteness and power in language. New York, NY: De Gruyter Mouton. https://doi.org/10.1515/9783110208344

McKeown, J., \& Zhang, Q. (2015). Socio-pragmatic influence on opening salutation and closing valediction of British workplace email. Journal of Pragmatics, 85, 92-107. https://doi.org/10.1016/j.pragma.2015.06.012

Mills, S. (2011). Discursive approaches to politeness and impoliteness. In Linguistic Politeness Research Group (Ed.), Discursive Approaches to Politeness (pp. 19-56). Boston: De Gruyter Mouton. https://doi.org/10.1515/9783110238679.19

Moghaddam, F., \& Harré, R. (2010). Words of conflict, words of war: How the language we use in political processes sparks fighting. Oxford: Praeger.

Moghaddam, F., \& Harré, R. (2010). Words, Conflicts, and Political Processes. In F. Moghaddam \& R. Harré (Eds.), Words of Conflict, Words of War: How the Language We Use in Political Processes Sparks Fighting (pp. 1-27). Oxford: Praeger.

Moghaddam, F., Harré, R., \& Lee, N. (2008). Global conflict resolution through positioning analysis. New York: Springer. https://doi.org/10.1007/978-0-387-72112-5

Mondada, L. (2017). Greetings as a device to find out and establish the language of service encounters in multilingual settings. Journal of Pragmatics, 126, 10-28. https://doi.org/10.1016/j.pragma.2017.09.003

Odebunmi, A. (2013). Greetings and Politeness in Doctor-Client Encounters in South Western Nigerian. Iranian Journal of Society, Culture and Language, 1(1), 102-115.

Olaoye, A. A. (2013). Sociolinguistic documentation of endangered ethnography of communication in Yoruba language. World Journal of English Language, 4(1), 32-40.

Rampton, B. (2006). Language in Late Modernity; Interaction in an Urban School. Cambridge: Cambridge University Press. https://doi.org/10.1017/CBO9780511486722

Rampton, B. (2015). Key concepts in the exploration of the interaction order. Working Papers in Urban Language and Literacies, 239, 1-8.

Rampton, B., Maybin, \& Roberts, C. (2015). Theory and Methods in Lingusitic Ethnography. In J. Snell, S. Shaw \& F. Copland (Eds.), Linguistic Ethnography; Interdisciplinary Explorations (pp. 14-49). Palgrave: Macmillan.

Rumenapp, J. C. (2016). Analyzing discourse analysis: Teachers' views of classroom discourse and student identity. Linguistics and Education, 35, 26-36. https://doi.org/10.1016/j.linged.2016.04.002

Tan, S.-L., \& Moghaddam, F. (2007). Reflexive positioning and culture. Journal for the Theory of Social Behaviour, 4(25), 387-400.

Tirado, F., \& Gálvez, A. (2007). Positioning Theory and Discourse Analysis: Some Tools for Social Interaction Analysis. Forum: Qualitative Social Research, 8(2), 1-18.

Upadhyay, S. R. (2010). Identity and impoliteness in computer-mediated reader responses. Journal of Politeness Research: Language, Behaviour and Culture, 6(1), 105-127. https://doi.org/10.1515/jplr.2010.006

van Der Bom, I., \& Mills, S. (2015). A discursive approach to the analysis of politeness data. Journal of Politeness Research, 11(2), 179-206. https://doi.org/10.1515/pr-2015-0008

van-Dijk, T. A. (2008). Discourse and power. New York: Palgrave Macmillan. https://doi.org/10.1007/978-1-137-07299-3 


\section{Appendix A}

\section{Transcription Keys Adapted from Gail Jefferson}

(.) A micropause - a pause of no significant length.

(0.7) A timed pause-long enough to indicate a time.

[ ] Square brackets show where speech overlaps.

(( )) An entry of ethnographic data.

Bold Denotes a raise in volume or emphasis.

$\uparrow \quad$ Rise in intonation

$\downarrow \quad$ Drop in intonation

\section{Copyrights}

Copyright for this article is retained by the author(s), with first publication rights granted to the journal.

This is an open-access article distributed under the terms and conditions of the Creative Commons Attribution license (http://creativecommons.org/licenses/by/4.0/). 